\begin{tabular}{|c|c|c|c|}
\hline$\Omega$ & $\square$ & $\equiv$ & (2) \\
\hline Stefano R. Del Giacco & $\begin{array}{l}\text { University of Cagliari, Dept } \\
\text { of Medical Sciences "M. } \\
\text { Aresu", Cagliari, Italy }\end{array}$ & $\begin{array}{l}\text { University of Cagliari, Dept } \\
\text { of Medical Sciences "M. } \\
\text { Aresu", Asse Didattico } \\
\text { "El", Cittadella } \\
\text { Universitaria, O9O42 } \\
\text { Monserrato (Cagliari), Italy }\end{array}$ & stedg@medicina.unica.it \\
\hline
\end{tabular}

\title{
Exercise-induced anaphylaxis: an update
}

\section{Summary}

Exercise-induced anaphylaxis (EIAn) is a rare and potentially fatal syndrome associated with exercise. It is the most serious and potentially life-threatening hypersensitivity phenomenon for athletes of all sports. Food-dependent EIAn (FDEIAn) shares the same symptoms, but ingestion of foods $2-3 \mathrm{~h}$ prior to exercise is crucial for its presentation. Attacks may seldom occur also if food ingestion is made 2-3 hours after exercise. Concomitant use of drugs, particularly aspirin and non-steroidal anti-inflammatory drugs, can worsen the clinical presentation. Clinical manifestations cover a wide range of symptoms, from pruritus to dyspnoea to vascular collapse. Differential diagnoses must be investigated when symptoms are unusual. Several pathogenetic theories have been formulated but the rarity of EIAn has not facilitated the efforts of scientists to find pathophysiological and immunological mechanisms that may account for these conditions. Diagnosis is mainly clinical and can be difficult. Validated protocols including skin prick testing together with food-exercise challenges, laboratory investigations looking for specific immunoglobulin $E$ or through allergy molecular diagnostics are often required. Preventative measures are of fundamental importance, in particular regarding education of patients, family/ carers, trainers and teammates. Use of adrenaline autoinjectors is also fundamental and their correct use must be taught to patients, doctors and nurses. Pharmacological preventative measures are not supported by sufficiently powered studies. Further research will be needed to investigate deeper the complexities of EIAn.

The term "anaphylaxis" was coined in 1902 by Charles Richet (1913 Nobel prize winner) and his colleague Paul Jules Portier to describe "the opposite of protection (phylaxis)" [1]. It represents the most serious and potentially life-threatening phenomenon in the field of allergology. Its clinical manifestations can be extremely varied, ranging from pruritus, erythema and urticaria to angioedema, gastrointestinal symptoms, laryngeal
Statement of interest None declared.
HERMES syllabus links: module B.1.1, B.1.10, B.17.2, B.17.4 


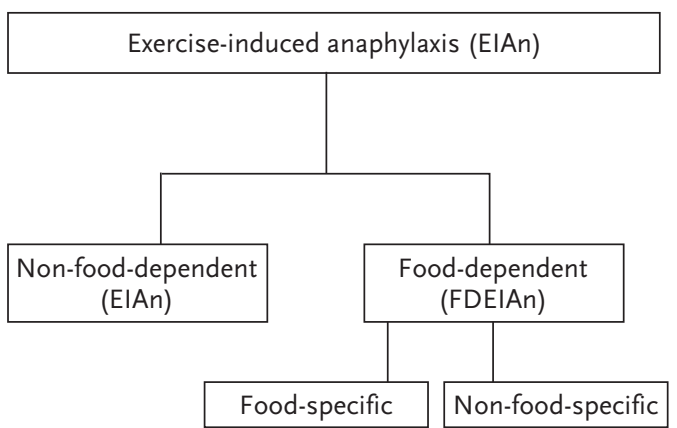

Figure 1

Types of EIAn.

symptoms and vascular collapse [2]. Exerciseinduced anaphylaxis (EIAn) is a rare, unpredictable, severe hypersensitivity reaction associated with exercise that shares the same clinical features with a classical anaphylactic reaction. It is a relatively recent syndrome, first described by MAULITZ et al. in 1979 [3] and named EIAn in 1980 by SHEFFER et al. [4]. As regards anaphylaxis in general, no exact incidence, based upon available data, can be established due to the different modalities of obtaining those data. Epidemiological studies show a lifetime prevalence variable of $0.05-2.0 \%$ [5] and a mortality rate of $1-2 \%$. It is reasonable to assume that $2-$ $15 \%$ of anaphylactic episodes are caused by or associated with exercise $[6,7]$.

Two types of EIAn are described (see fig. 1): 1) non-food-dependent EIAn; and 2) fooddependent EIAn (FDEIAn), further divided into "food-specific" and "non-food-specific".

\section{Clinical aspects}

EIAn and FDEIAn share a common clinical picture and diagnosis can be made when patients have anaphylactic symptoms associated with exercise. Symptoms usually (in
$90 \%$ of cases) occur within 30 minutes after initiating the exercise, but can also begin later and occasionally just after the exercise. Symptoms vary in severity and can be limited to the "prodromic phase", to generalised urticaria or progress towards systemic anaphylaxis (fig. 2). Some patients may also experience headache that can persist for hours to days after an EIAn attack $[4,8]$ Fatal or near-fatal reactions are rarely reported [9]; fatalities may however be underestimated due to the rarity of the disorder and the difficulty of making a post mortem diagnosis of EIAn [10]. EIAn occurs in all ages, most often in adolescents and young adults, but occasionally in children and in older adults. There is a 2:1 ratio of females versus males described in two epidemiological studies [8, 11]; some authors identify the menstrual cycle as a triggering factor $[12,13]$. It is more common in atopic individuals. EIAn has been described both in high-performance athletes and in individuals undertaking only occasional exercise. In general EIAn occurs following submaximal exercise of a relatively short duration. Some activities such as jogging, aerobics, walking and tennis/squash have a higher incidence than others $[8,1]$, but also dancing or other sub-maximal non-sports-related physical activities (for example, raking garden leaves) have been reported as triggers for EIAn [14]. Athletes should be warned that EIAn may occur during all phases of exercise including the warm-up, initiation phase, maintenance or cooling down phase.

It appears that there is no one consistent exercise-associated factor, e.g. ambient temperature, humidity or anticipation (i.e. planned versus spontaneous activity), even though WADE et al. [11] report an epidemiological association of EIAn with warm environment

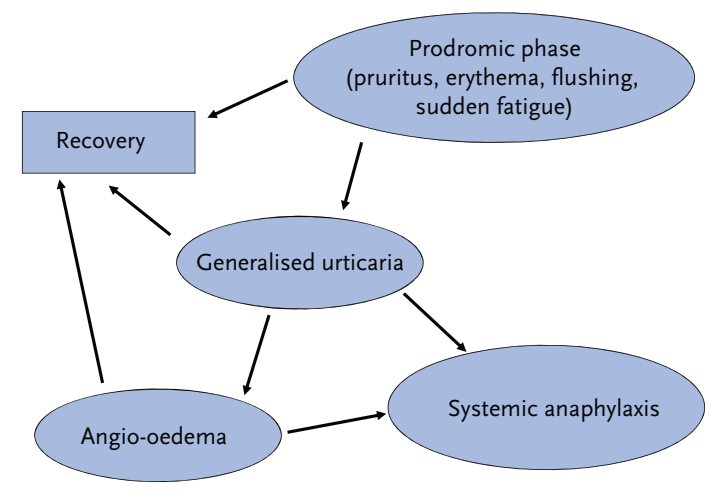

Figure 2

Phases of anaphylaxis. 
( $64 \%$ of cases), high humidity ( $32 \%$ ) and cold environments (23\%).

In FDEIAn, when exercising, symptoms may arise minutes to a few hours after the consumption of foodstuffs, which thus represent the predisposing factor. In rare cases, symptoms may arise with food intake shortly after exercising. In FDEIAn patients, exercise and food are independently tolerated. There are two subtypes of FDEIAn: food-specific, in which a specific and identified food is able to induce symptoms in connection with exercise and non-food-specific, in which any kind of meal can be responsible for the reaction. The literature includes cases of EIAn following the ingestion of a wide variety of foods, including seafood, celery, milk, cheese, vegetables and fruit in general; in the European population, tomatoes, cereals and peanuts seem to be the more common [15], while wheat, shrimps and shellfish are the most common in Japan [16]. Implicated foods may be culturally influenced and are usually different from those associated with food allergy alone (peanut, tree nuts, milk and egg) $[15,17,18]$.

FDEIAn following the consumption of snails in patients demonstrating skin prick testing positivity to house dust mites has also been described [19], the cross-reactivity between aeroallergens and foodstuffs is well known; however, individual strategies, from modifying one's exercise regimen to avoiding known precipitants, may mitigate symptoms: in one 10-year study, episode severity stabilised in $46 \%$ of patients, regressed in $47 \%$ and worsened in $7 \%$ [14].

In athletes, it is important to consider the role of food allergies that may be associated with food allergens peculiar to exercise, e.g. commercial rehydration fluids, such as soya and animal-derived gelatine, omega-5-gliadin in carbohydrate meals eaten for "carbo loading" [20], nut protein in massage oils. Recent findings related to mammalian sugars (oligosaccharide galactose $\alpha$-1, 3-galactose) allergic reactions are interesting, as here too there is a link to exercise as a co-factor in some case reports; these reactions may occur some hours after ingestion which is atypical forimmunoglobulin (Ig)E-mediated food-induced allergic reactions [21, 22]. As previously mentioned, FDEIAn usually occurs after the ingestion of foods but some reports indicate that symptoms may also arise if food is ingested after the exercise, suggesting that the coexistence of triggering factors may be more important than their sequence $[9,23]$. Some authors also describe cases in which FDEIAn depends mainly on the amount and not just on the type of the specific foodstuff ingested $[24,25]$. Furthermore, given the frequent use by athletes of non-steroidal anti-inflammatory drugs (NSAIDs) as pain killers, attention should be paid because of the so-called "summation anaphylaxis", where the concomitant medication use (in particular aspirin) may represent an additional facilitating factor for the anaphylactic reaction in a dosedependent manner $[7,26,27]$.

\section{Diagnosis and differential diagnoses}

Diagnosis of EIAn is clinical, and the clinical diagnosis may benefit from the consensus criteria for anaphylaxis proposed in 2005 [43]. Exercise and the identification and timing of foods ingested during the preceding 24 hours are noted in the history. The physical examination may be helpful to determine whether the patient appears atopic (as are the majority of children and adolescents with FDEIAn) [28]. Allergy questionnaires specific for athletes may help to assess the hidden atopic status of sports performers [29]. The physical examination should include a detailed assessment of the endocrine, cardiac and neurological systems. The respiratory and dermatological examination should document the presence or absence of asthma and/or other systemic medical conditions. In particular, care should be taken to exclude lesions suggestive of mastocytosis [10]. Allergy testing (SPT and/or specific (gE) is fundamental in FDEIAn and may follow a well-defined protocol, first described by Romano et al. [30]. Patients with suspected food-dependent EIAn must undergo prick testing for a wide panel of commercial allergens (airborne allergens and food allergen, including seasoning foods) and fresh food (prick-by-prick), as well as specific IgE search. In particular, measurement of specific IgE to omega-5 gliadin (Tri a 19) can be useful in the detection of wheat-induced FDEIA and may detect cases that would otherwise be missed using standard wheat allergy tests (skin prick test and specific-lgE) [31-34]. The molecular diagnosis of allergy, available with microarraybased panel of allergens and panallergens [35] (ISAC ${ }_{\mathbb{B}}$; Phadia, Sweden) can now be added to the well-established protocols [36]. On the 


\section{Educational questions}

1) All the patients with food allergy present FDEIAn

a) True

b) Only when

environmental

humidity is over $60 \%$

c) Only when allergy relates to vegetables

d) False

2) EIAn intensity is related to the amount of food ingested

a) True

b) Only in some case reports but in general not true

c) Only when a "summation" anaphylaxis occurs 3) Positivity to skin prick-testing alone suffice for the diagnosis of EIAn

a) Only if the positivity is related to food allergens

b) Only if the positivity is related to panallergens

c) True

d) False

4) Aspirin

administration may be a preventive measure for EIAn

a) Only if administered together with cetirizine

b) Only in patients without Adverse-Drug Reactions to Aspirin and NSAIDs

c) Never: it is a precipitating factor for EIAn

d) Always: it reduces systemic inflammation, thus preventing EIAn basis of these findings, treadmill stress tests with progressively increasing speeds can be administered to patients 90 minutes after a meal containing none of the foods associated with skin-test or specific IgE/ISAC ${ }_{B}$ positivity (food-exercise challenge (FEC)) and $90 \mathrm{~min}$ utes after the same meal with the addition of one of the foods suspected of causing the FDEIAn reaction (suspected food exercise challenge (SFEC)). Test must be interrupted immediately if the patient begins to experience specific symptoms (pruritus, erythema, lacrimation, conjunctival injection or abdominal cramps); otherwise, the test can be continued until muscular exhaustion occurs. Modified exercise dietary tests are frequently required for the diagnosis of FDEIAn, e.g. eliminationreintroduction diets (with and without ongoing exercise), open food-exercise challenges (OFEC) and double-blind placebo-controlled food exercise challenge (DBPCFEC) [10], the latter being considered as the gold standard. Confounding factors unique to the patient's previous FDEIAn presentation(s) may be required to reproduce FDEIAn, e.g. particular forms of exercise or extreme environments. Similar environmental conditions as those which induced the FDEIA presentation(s) would represent the ideal setting for exercise testing. A positive OFEC or atypical symptoms always require confirmation by means of a DBPCFEC [10].

The usefulness of serum tryptase dosage is limited but can be useful to exclude nonmast-cell related conditions: persistently elevated levels of tryptase may in fact suggest a systemic process like mastocytosis [10, 37].

Periodic re-evaluation for loss of sensitivity to food and/or exercise is recommended, as the natural history of FDEIAn is unpredictable.

Differential diagnoses must be taken into consideration when symptoms and signs are not typical, and the clinician has to carefully explore the wide list of differential diagnoses of conditions that may be associated with exercise (see table 1), e.g. the so-called "aquagenic anaphylaxis" [38] and the various forms of exercise-induced urticaria (EIU), such as EIU itself, physical urticaria (or urticaria factitia or dermographism), and other forms induced by cold or heat, by compression, by exposure to ultraviolet rays, by vibrations and by water, as well as the cholinergic form [2]. Drowning from aquagenic anaphylaxis may occur in cold water. Cold-induced and cholinergic urticarias also are important considerations in the exercise setting. Cold urticaria occurs on contact with cold air, fluids or objects, placing swimmers or skiers at increased risk. Cold urticaria can be confirmed if an ice cube placed on the skin for up to 20 minutes induces urticaria during rewarming. Cholinergic urticaria occurs within minutes after elevation of the body temperature, regardless whether passive (hot shower) or active (exercise), and may progress to include angio-oedema, bronchospasm and hypotension. Notably, the diameters of cholinergic urticaria wheals are $<5 \mathrm{~mm}$, whereas those associated with El-anaphylaxis are substantially larger. Solar, aquagenic, vibratory, dermographic and/or pressure physical urticarias also may be associated with EIAn [18]. Other differential diagnoses include minor aspects of allergic disorders in connection with exercise-related contact dermatitis due to sports-related substances or situations and other general diseases (see table 1).

\section{Pathophysiology}

Pathophysiological mechanisms of EIAn and FDEIAn are still unclear, and many hypotheses have been proposed. All authors seem to agree on the role of mast-cell-derived vasoactive mediators, such as histamine, peptido-leukotrienes and platelet activating factor. A "mastcell instability" has been described in subjects with EIAn and FDEIAn [14, 39] and the increase in histamine plasma levels has been clearly documented [40]. Current main hypotheses include alterations in plasma osmolality and $\mathrm{pH}$, exercise-induced gut increased permeability, blood flow redistribution and increased tissue transglutaminase activity. RoBsONANSLEY and DU TOIT [7] recently considered each of these hypotheses in the context of advances in our understanding of exercise physiology. EIAn is generally reported following sub-maximal exercise of a relatively short duration. This fact alone seems to eliminate the majority of the proposed pathophysiological mechanisms, as significant physiological changes in blood $\mathrm{pH}$ and osmolality do not occur at sub-maximal levels of physical activity. Short duration exercise results in significant redistribution of blood from the gut (where mucosal mast cells are phenotypically tolerant to allergenic peptides) to other locations, such as the skin or skeletal muscle where "gut-tolerated" peptides are redistributed to sensitised, "phenotypically different" 


\begin{tabular}{|c|c|}
\hline Swelling/angio-oedema & $\begin{array}{l}\text { - Chronic urticaria and angioedema } \\
\text { - ACEI medication intake } \\
\text { - Complement deficiency/dysfunction }\end{array}$ \\
\hline Cutaneous/flushing & $\begin{array}{l}\text { - Cholinergic urticaria } \\
\text { - EIU, physical urticaria secondary to pressure, } \\
\text { vibration, sunlight, sweat } \\
\text { - Physiological flushing } \\
\text { - Scromboid fish poisoning } \\
\text { - Mastocytosis } \\
\text { - Rare: peptide secreting tumours (Carcinoid, } \\
\text { VIPoma). Medullary carcinoma of thyroid, or } \\
\text { phaechromocytoma }\end{array}$ \\
\hline Neurological & $\begin{array}{l}\text { - Epileptic seizure } \\
\text { - Vasovagal episodes }\end{array}$ \\
\hline Vascular & $\begin{array}{l}\text { - Cardiac abnormalities, e.g. arrhythmias } \\
\text { - Vasovagal episodes } \\
\text { - Systemic inflammatory syndromes }\end{array}$ \\
\hline Upper airway symptoms & $\begin{array}{l}\text { - Vocal cord dysfunction } \\
\text { - Panic disorders }\end{array}$ \\
\hline Lower airway symptoms & - Exercise-induced asthma \\
\hline
\end{tabular}

mast cells, inducing either a transient loss of tolerance or an amplification of a low-grade allergic reaction, thus presenting with EIAn [7]. All these hypotheses are summarised in table 2. Whatever the mechanism, allergists have taken these exercise-associated immune changes into consideration in clinical practice for a long time. For example, patients undergoing venom or pollen immunotherapy are routinely advised to refrain from exercise for some time after administration. Similar findings and advices are emerging from the many oral tolerance induction studies that are underway [41, 42].

\section{Management}

Therapeutic interventions for EIAn/FDEIAn include preventive and acute measures [43, 44]. Prophylactic management for El-anaphylaxis is to first avoid the trigger(s), particularly foods. Specific food allergens should be avoided for 4-6 $\mathrm{h}$ prior to exercise and $1 \mathrm{~h}$ after. A dietician may be helpful. When FDEIAn is non-specific, an abstinence interval of $2-4 \mathrm{~h}$ is generally adequate, but individual variation is considerable. Also in this case foodstuff must be avoided $\mathrm{i} h$ after exercise. For children with food allergy, their teachers, close friends and relatives may need special counselling. A slow, supervised return to exercise should be encouraged, especially in young athletes. Sometimes, it may be necessary to totally eliminate the food from the diet of athletes and physically active young children in order to achieve a successful result [22]. Avoidance of $\beta$-blockers, angiotensin converting-enzyme inhibitors and angiotensinreceptor blockers should be considered, because these drugs may increase the severity of anaphylaxis. Aspirin and NSAIDs, which increase gastrointestinal permeability, should also be avoided.

Some papers report that pre-treatment with some drugs may prevent EIAn: isoprostol [45], ketotifen [46], combined cetirizine-montelukast [47], antileukotrienes, sodium chromoglycate and oral corticosteroids [7] show their efficacy in some case reports. Evidence, however, is not sufficient to recommend the use of any medication prior to exercise. Food avoidance and the other non-pharmacological preventive measures are able to guarantee a more prudent approach. Anti-doping regulations must however be taken into consideration when treating competitive athletes. The 


\section{Contemporary hypotheses for EIAn}

\section{Physiological basis of hypotheses}

\section{Exercise physiology in} context of EIAn
Future research direction.
Changes in plasma osmolality during exercise $\uparrow$ basophil histamine release. $340 \mathrm{mOsm}$ associated with $\uparrow$ in basophil histamine release in FDEIAn.
Exercise can $\uparrow$ plasma osmolarity. Dramatic changes in osmolarity can alter basophil histamine release. relatively stable during shortterm, low intensity exercise. $5 \%$ loss of body mass through dehydration required to achieve osmolality of 305 mOsm.
Plasma osmolarity is

$\begin{array}{ll}\uparrow \text { acidity in blood results in } & \text { Exercise induces metabolic/ } \\ \text { increased mast cell degranulation } & \text { lactic acidosis. } \mathrm{pH} \text { 7 provides } \\ \text { as shown by protective effect of } & \text { optimal conditions for mast } \\ \text { sodium bicarbonate in FDEIAn } & \text { cell degranulation. }\end{array}$
during exercise.

\section{$\uparrow$ exercise-induced gut} permeability $(\mathrm{Gl})$ results in appearance of gliadin peptides in WDEIA.

\author{
Exercise can $\uparrow \mathrm{Gl}$ and \\ potentially $\uparrow$ absorption of \\ allergenic peptides.
}

\section{Supramaximal exercise associated with lactic acidosis Acidosis is unlikely to occur in the context of EIAn. \\ Only very prolonged exercise is associated with increases in $\mathrm{Gl}$. Exercise for 90 mins at $70 \% \mathrm{VO}_{2 m a x} \downarrow \mathrm{GI} \uparrow \mathrm{Gl}$ is unlikely to occur in the context of EIAn.}

Effect of minor shifts in osmolarity on basophil degranualtion warrants further investigation.

\section{Short-term, low intensity exercise results in slight, transient $\uparrow$ in inflammatory cytokines, free radicals or cortisol. No evidence of tTG/ allergen complexes in circulation in EIAn.}

Changes in muscle $\mathrm{pH}$ greater than blood, prophylactic effect of sodium bicarbonate warrants further investigation.

Caution: aspirin, NSAIDs, alcohol ingested can $\uparrow \mathrm{Gl}$ permeability during or prior to exercise
Exercise-induced $\uparrow$ in tissue transglutaminase (tTG) activity results in post-digestion allergenic peptide aggregation. homeostatic disruption and associated $\uparrow$ in inflammatory cytokine, free radicals and cortisol release. Dysregulated tTG results in fibrosis, autoimmune disorders.
Determination of lowest concentration of cytokines to $\uparrow$ tTG required.
Exercise results in altered blood flow from the viscera to the active tissues. Mast cell heterogeneity has been demonstrated in a number of tissues in humans.
Mild to severe exercise alters blood flow distribution with greater percentage of cardiac output going to active tissues and reduction to viscera.

\section{Hypothesis warrants further} investigation in EIAn patients vs healthy controls. exposure of allergen to
phenotypically different mast cells.

permission from the publisher. updated list of banned drugs can be found on the World Anti-Doping Agency (WADA) website (www.wada-ama.org).

Acute management aims to solve the cardiovascular (hypotension) and respiratory manifestations. Doctors should teach athletes on how to recognise their first symptoms and signs of EIAn and immediately discontinue exercise. They should learn to assume the Trendelenburg position to facilitate perfusion of vital organs in the face of hypotension and to use auto-injectable adrenaline intramuscularly into the lateral thigh to improve airflow and vascular integrity [18]. It is recommended for teams or for sporting facilities to have at least one auto-injectable adrenaline device available in their emergency kit. Once medical emergency personnel become involved, the management of anaphylaxis should proceed according to published guidelines $[48,49]$.

\section{Conclusions}

If the natural history of EIAn is still not clarified, the fact remains that it is a rare, but potentially fatal clinical condition for athletes. Several pathogenetic hypotheses are more prevalent and "realistic" than others (e.g. gastro-intestinal enhanced permeability) but they require further investigation to be generalised to the full EIAn 
population. Personalised emergency plans and medications are of high importance and must be issued after the patient and his family/carers (but also trainers and teammates) have undergone a training in the identification and treatment of anaphylaxis, particularly regarding the use of adrenaline auto-injectors [50].

With a careful prevention and management plan, a gradual return to exercise can be safely achieved for most EIAn patients.

\section{Key learning points}

- EIAn is the most serious and potentially life-threatening hypersensitivity phenomenon for athletes.

- Food ingestion prior to or after exercise is the causative factor in FDEIAn.

- The diagnostic work-up consists in careful history, skin allergy testing, laboratory investigations and food-exercise challenges.

- Preventive measures for FDEIAn include food avoidance up to 6 hours before exercising and 1 hour after.

- Preventive measures and good management plans allow a return to exercise for most of the patients.

\section{References}

1. Richet C. Anaphylaxis, Liverpool: Constable \& Co., 1913.

2. Del Giacco SR, Manconi PE, Del Giacco GS. Allergy and sports. Allergy 2001; 56: 215-223.

3. Maulitz RM, Pratt DS, Schocket AL. Exercise-induced anaphylactic reaction to shellfish. J Allergy Clin Immunol 1979; 63: 433-4.

4. Sheffer AL, Austen KF. Exercise-induced anaphylaxis. J Allergy Clin Immunol 1980; 66: 106-111.

5. Tang ML, Osborne N, Allen K. Epidemiology of anaphylaxis. Curr Opin Allergy Clin Immunol 2009; 9: $351-356$.

6. Lieberman P. Epidemiology of anaphylaxis. Curr Opin Allergy Clin Immunol 2008; 8: 316-320.

7. Robson-Ansley P, Du Toit G. Pathophysiology, diagnosis and management of exercise-induced anaphylaxis. Curr Opin Allergy Clin Immunol 2010; 10: 312-317.

8. Shadick NA, Liang MH, Partridge AJ, et al. The natural history of exercise-induced anaphylaxis: survey results from a 10-year follow-up study. J Allergy Clin Immunol 1999; 104: 123-127.

9. Barg W, Medrala W, Wolanczyk-Medrala A. Exerciseinduced anaphylaxis: an update on diagnosis and treatment. Current allergy and asthma reports 2011; 11: 45-51.

10. Du Toit G. Food-dependent exercise-induced anaphylaxis in childhood. Pediatr Allergy Immunol 2007; 18: $455-463$.

11. Wade JP, Liang MH, Sheffer AL. Exercise-induced anaphylaxis: epidemiologic observations. Prog Clin Biol Res 1989; 297: 175-182.

12. Dohi M, Suko M, Sugiyama $H$, et al. Food-dependent, exercise-induced anaphylaxis: a study on 11 Japanese cases. J Allergy Clin Immunol 1991; 87: 34-40.

13. Bito T, Kanda E, Tanaka M, et al. Cows milkdependent exercise-induced anaphylaxis under the condition of a premenstrual or ovulatory phase following skin sensitization. Allergol Int 2008; 57: 437-439.
14. Castells MC, Horan RF, Sheffer AL. Exercise-induced Anaphylaxis. Curr Allergy Asthma Rep 2003; 3: 15-21.

15. Romano A, Di Fonso M, Giuffreda F, et al. Fooddependent exercise-induced anaphylaxis: clinical and laboratory findings in 54 subjects. Int Arch Allergy Immunol 2001; 125: 264-272.

16. Harada S, Horikawa T, Icihashi M. [A study of fooddependent exercise-induced anaphylaxis by analyzing the Japanese cases reported in the literature]. Arerugi 2000; 49: 1066-1073.

17. Morita E, Kunie K, Matsuo H. Food-dependent exercise-induced anaphylaxis. J Dermatol Sci 2007; 47: 109-117.

18. Schwartz LB, Delgado L, Craig T, et al. Exerciseinduced hypersensitivity syndromes in recreational and competitive athletes: a PRACTALL consensus report (what the general practitioner should know about sports and allergy). Allergy 2008; 63: 953-961.

19. Longo G, Barbi E, Puppin F. Exercise-induced anaphylaxis to snails. Allergy 2000; 55: 513-514.

20. Morita E, Matsuo H, Mihara S, et al. Fast omegagliadin is a major allergen in wheat-dependent exercise-induced anaphylaxis. J Dermatol Sci 2003; 33: 99-104.

21. Commins SP, Satinover SM, Hosen J, et al. Delayed anaphylaxis, angioedema, or urticaria after consumption of red meat in patients with IgE antibodies specific for galactose-alpha-1,3-galactose. J Allergy Clin Immunol 2009; 123: 426-433.

22. Del Giacco SR, Carlsen KH, Du Toit G. Allergy and sports in children. Pediatr Allergy Immunol 2012; 23: $11-20$.

23. Wolanczyk-Medrala A, Barg W, Radlinska A, et al. Food-dependent exercise-induced anaphylaxissequence of causative factors might be reversed. Ann Agric Environ Med 2010; 17: 315-317.

24. Hanakawa $Y$, Tohyama M, Shirakata $Y$, et al. Fooddependent exercise-induced anaphylaxis: a case related to the amount of food allergen ingested. Br J Dermatol 1998; 138: 898-900. 
25. Inoue N, Yamamoto A, Matsumoto S, et al. [Fooddependent exercise-induced anaphylaxis that was difficult to evoke by a provocation test]. Arerugi 2011; 6o: $1560-1566$

26. Nakamura K, Inomata N, Okawa T, et al. [Case of food-dependent exercise-induced anaphylaxis diagnosed by the provocation test with cuttlefish after the pretreatment with $1.5 \mathrm{~g}$ of aspirin]. Arerugi 2010; 59: 1634-1641.

27. van Wijk RG, de Groot H, Bogaard JM. Drugdependent exercise-induced anaphylaxis. Allergy 1995; 50: 992-994.

28. Tanaka S. An epidemiological survey on fooddependent exercise-induced anaphylaxis in kindergartners, schoolchildren and junior high school students. Asia Pac J Public Health 1994; 7: 26-30.

29. Bonini M, Braido F, Baiardini I, et al. AQUA: Allergy Questionnaire for Athletes. Development and validation. Med Sci Sports Exerc 2009; 41: 1034-1041.

30. Romano A, Di Fonso M, Giuffreda F, et al. Diagnostic work-up for food-dependent, exercise-induced anaphylaxis. Allergy 1995; 50: 817-824.

31. Palosuo K, Alenius $\mathrm{H}$, Varjonen $\mathrm{E}$, et al. Rye gamma70 and gamma-35 secalins and barley gamma-3 hordein cross-react with omega-5 gliadin, a major allergen in wheat-dependent, exercise-induced anaphylaxis. Clin Exp Allergy 2001; 31: 466-473.

32. Palosuo K, Varjonen E, Nurkkala J, et al. Transglutaminase-mediated cross-linking of a peptic fraction of omega-5 gliadin enhances IgE reactivity in wheat-dependent, exercise-induced anaphylaxis. J Allergy Clin Immunol 2003; 111: 1386-1392.

33. Lehto $\mathrm{M}$, Palosuo K, Varjonen $\mathrm{E}$, et al. Humoral and cellular responses to gliadin in wheat-dependent, exercise-induced anaphylaxis. Clin Exp Allergy 2003; 33: 90-95.

\section{Suggested}

\section{answers}

1. d.

2. b.

3. d.

4. C.

34. Palosuo K, Varjonen E, Kekki OM, et al. Wheat omega-5 gliadin is a major allergen in children with immediate allergy to ingested wheat. J Allergy Clin Immunol 2001; 108: 634-638.

35. Hauser M, Roulias A, Ferreira F, et al. Panallergens and their impact on the allergic patient. Allergy Asthma Clin Immunol 2010; 6: 1.

36. Sastre J. Molecular diagnosis in allergy. Clin Exp Allergy 2010; 40: 1442-1460. reactions: An emergency department-based study. J Allergy Clin Immunol 2000; 106: 65-71.

38. Briner WW Jr. Physical allergies and exercise. Clinical implications for those engaged in sports activities. Sports Med 1993; 15: 365-373.

39. Castells MC, Horan RF, Sheffer AL. Exercise-induced anaphylaxis (EIA). Clin Rev Allergy Immunol 1999; 17: $413-424$.

40. Sheffer AL, Soter NA, McFadden ER Jr, et al. Exerciseinduced anaphylaxis: a distinct form of physical allergy. J Allergy Clin Immunol 1983; 71: 311-316.

41. Varshney P, Steele PH, Vickery BP, et al. Adverse reactions during peanut oral immunotherapy home dosing. J Allergy Clin Immunol 2009; 124: 1351-1352.

42. Calvani M, Sopo SM. Exercise-induced anaphylaxis caused by wheat during specific oral tolerance induction. Ann Allergy Asthma Immunol 2007; 98: 98-99.

43. Sampson HA, Munoz-Furlong A, Bock SA, et al. Symposium on the definition and management of anaphylaxis: summary report. J Allergy Clin Immunol 2005; 115: 584-591.

44. Simons FE, Frew AJ, Ansotegui IJ, et al. Risk assessment in anaphylaxis: current and future approaches. J Allergy Clin Immunol 2007; 120: Suppl. 1, S2-S24.

45. Takahashi A, Nakajima K, Ikeda M, et al. Pretreatment with misoprostol prevents food-dependent exercise-induced anaphylaxis (FDEIA). Int J Dermatol 2011; 50: 237-238.

46. Choi JH, Lee HB, Ahn IS, et al. Wheat-dependent, exercise-induced anaphylaxis: a successful case of prevention with ketotifen. Ann Dermatol 2009; 21: 203-205.

47. Peroni DG, Piacentini GL, Piazza M, et al. Combined cetirizine-montelukast preventive treatment for fooddependent exercise-induced anaphylaxis. Ann Allergy Asthma Immunol 2010; 104: 272-273.

37. Lin RY, Schwartz LB, Curry A, et al. Histamine and tryptase levels in patients with acute allergic
48. Lieberman P, Nicklas RA, Oppenheimer J, et al. The diagnosis and management of anaphylaxis practice parameter: 2010 update. J Allergy Clin Immunol 2010; 126: $477-480$.

49. Simons FE. Anaphylaxis pathogenesis and treatment. Allergy 2011; 66: Suppl. 95, 31-34.

50. Frew AJ. What are the 'ideal' features of an adrenaline (epinephrine) auto-injector in the treatment of anaphylaxis? Allergy 2011; 66: 15-24. 